\title{
Ensino de línguas e formação profissional em contexto de fronteira: motivações e representações do francês no Amapá.
}

\author{
Mileny Távora de Mendonça ${ }^{1}$ \\ Kelly Cristina Nascimento Day ${ }^{2}$
}

\begin{abstract}
Resumo
O presente trabalho, face às novas orientações da política linguística educativa brasileira que privilegia o ensino da língua inglesa em todo o território nacional, apresenta um estudo exploratório-descritivo das motivações e representações linguísticas de estudantes de Francês Língua Estrangeira (FLE) no Amapá e propõe uma reflexão sobre o ensino de línguas e a formação para o trabalho em um contexto de fronteira. Fundamentado em pressupostos da Política Linguística Educativa, cotejando conceitos de motivação e representação linguística, a pesquisa busca correlacionar a demanda pela aprendizagem de uma LE aos aspectos geopolíticos que circunscrevem a escolha linguística dos falantes em uma região fronteiriça. A pesquisa de natureza qualiquantitativa, teve como instrumento de pesquisa o questionário semiestruturado, com questões abertas e fechadas. Foram aplicados 230 questionários a estudantes de francês no Amapá. Os resultados indicam que o ensino/aprendizagem do francês no Amapá está diretamente relacionado às perspectivas de trabalho da população local e especialmente de profissionais em busca de lugar no mercado de trabalho.
\end{abstract}

Palavras-chave: Formação profissional. Ensino de Línguas.Fronteiras.

\section{Resumen}

El presente trabajo, frente a las nuevas orientaciones de la política lingüística educativa brasileña, que privilegia la enseñanza de la lengua inglesa en todo el territorio nacional, presenta un estudio exploratorio-descriptivo de las motivaciones y representaciones lingüísticas de estudiantes de Francés Lengua Extranjera (FLE) Amapá y propone una reflexión sobre la enseñanza de idiomas y la formación para el trabajo en un contexto de frontera. La investigación busca correlacionar la demanda por el aprendizaje de una LE a los aspectos geopolíticos que circunscriben la elección lingüística de los hablantes en una región fronteriza. Fundamentado en supuestos de la Política Lingüística Educativa, cotejando conceptos de motivación y representación lingüística, la investigación busca correlacionar la demanda por el aprendizaje de una LE a los aspectos geopolíticos que circunscriben la elección lingüística de los hablantes en una región fronteriza. La investigación de naturaleza cualiquantitativa, tuvo como instrumento de investigación el cuestionario semiestructurado, con cuestiones abiertas y cerradas. Se aplicaron 230 cuestionarios a estudiantes de francés en Amapá. Los resultados indican que la enseñanza / aprendizaje del francés en Amapá está directamente relacionada con las perspectivas de trabajo de la población local y especialmente de profesionales en busca de lugar en el mercado de trabajo.

Palabras clave: Formación profesional. Enseñanza de lenguas. Fronteras.

\section{Introdução}

\footnotetext{
${ }^{1}$ Mestra em Letras e em Didática das Línguas. Atualmente é professora da Universidade do Estado do Amapá UEAP. E-mail: milenymendonca@hotmail.com; mileny.mendonca@ueap.edu.br

${ }^{2}$ Doutora em Estudos da Linguagem. Atualmente é professora adjunta da Universidade do Estado do Amapá UEAP. E-mail: kelly.day@ueap.edu.br
} 
Onde quer que se esteja, a vida local se vê cada vez mais afetada pelos efeitos de um mundo globalizado, em que a comunicação exerce função protagonista. Nas empresas, nas escolas, nas ruas, nas relações comerciais, nas mídias e redes sociais, as línguas estrangeiras se mostram cada dia mais necessárias e o cidadão do século XXI busca meios linguísticos e tecnológicos para lidar com as situações que se Ihe apresentam. Porém, seja no âmbito de uma política linguística impositiva, seja pela livre determinação de uma sociedade, a escolha de uma língua estrangeira depende de um conjunto de fatores diretamente relacionados às necessidades dos aprendizes e aos usos sociais que determinadas línguas desempenham entre grupos distintos, como ocorre no caso de comunidades linguísticas em regiões de fronteira.

Nesses espaços fronteiriços, as línguas desempenham diferentes papeis sociais, agindo entre outros, na marcação das distâncias entre os povos, no contato intercultural, no reforço das identidades, nas negociações políticas, nos intercâmbios comerciais e nas trocas interpessoais. O papel do conhecimento das línguas nesses processos é tributário da leitura que as pessoas fazem das relações estabelecidas, podendo tanto atuar em favor da integração quanto no distanciamento.

No composto diverso e multilíngue que constitui a faixa de fronteira brasileira, a singularidade linguística do estado do Amapá reside no fato de ser a única fronteira brasileira confluente com um território francófono, local onde as políticas de ensino de línguas (português e francês) têm origem nas práticas diárias, no contato linguístico e no acordo de cooperação transfronteiriça pactuado entre Brasil e França, Amapá e Guiana Francesa em meados dos anos 1990.

Na esfera da cooperação educativa prevista no Acordo-Quadro, além da introdução paulatina da língua francesa (LF) no currículo das escolas de ensino fundamental e médio, o ensino da LF passa a ser assegurado no Estado do Amapá pelo Centro Estadual de Língua e Cultura Francesa Danielle Mitterrand (CELCFDM), criado em 1998 para ofertar, de forma gratuita, o ensino da língua francesa a toda a comunidade que manifestasse interesse pela aprendizagem da língua.

Símbolo institucional de uma política linguística educativa adotada no âmbito da 
cooperação transfronteiriça, o CELCFDM passa a reunir uma diversidade de aprendentes, representativa das diferentes funções do francês nos domínios sociais da fronteira e das representações construídas em torno da aprendizagem daquela língua no Amapá.

Ocorre que as mudanças protagonizadas na política de ensino de línguas no Brasil, ocorridas respectivamente em $2005^{3}$ (Lei 11.161) e $2017^{4}$ (Lei 13.415), impactam diretamente no ensino de francês no Amapá, ainda que essa língua esteja diretamente vinculada às práticas sociais e à qualificação para o trabalho reveladas nas representações, motivações e usos sociais do francês nessa fronteira.

Nesse contexto, este estudo propõe um duplo olhar para a questão, objetivando mapear o perfil socioeconômico e profissional dos aprendentes debutantes do curso de francês ofertado no CELCFDM e identificar as motivações e representações que impulsionam a aprendizagem da LF no Amapá. Os dados obtidos permitem correlacionar o interesse social pela aprendizagem da LF no Amapá e a qualificação profissional pretendida pelos aprendentes.

Este artigo está organizado em quatro partes: inicialmente inscreve-se este estudo no âmbito da política linguística educativa; em seguida apresentam-se as noções de representação social e linguística e de motivação; na terceira sessão descreve-se a metodologia e o contexto da pesquisa e, posteriormente, apresentam-se os resultados da análise dos dados. Nas considerações finais, as contradições entre a demanda social, a representação dos aprendentes e a política linguística em vigor são denotadas segundo os pressupostos teóricos de base.

\section{Ensino de línguas Estrangeiras no contexto da Política Linguística Educativa Brasileira}

O ensino de línguas estrangeiras no Brasil, ainda que remonte aos idos da catequização indígena, circunscreve-se de muitas controvérsias, seja nas práticas, nos discursos, seja nos objetivos pretendidos ou nas políticas linguísticas adotadas. O ensino de

\footnotetext{
${ }^{3} 2005$ é o ano da promulgação da Lei 11.161 que determinou a oferta obrigatório da língua espanhola no ensino médio no Brasil. Antes disso, o francês era a segunda LE mais presente no ensino secundário no Amapá. ${ }^{4} \mathrm{Em} \mathrm{2017}$, fica estabelecida a obrigatoriedade do ensino da língua inglesa em todo o território nacional.
} 
línguas estrangeiras (LE), objeto central do campo da Política Linguística Educativa, compreendida como um componente particular de uma Política Linguística cujo domínio de aplicação envolve especialmente o ensino de línguas (PETITJEAN, 2006), se reveste de múltiplos discursos e de rara convergência com a diversidade linguística brasileira e seus contextos multifacetados.

Em tempos de multilinguismo em esfera global, os processos regulatórios das políticas linguísticas educativas buscam cada vez mais legitimar processos e práticas que assegurem a conformação de identidades supranacionais homogêneas, uniformizadoras e convergentes (PACHECO \& PEREIRA, 2006), para a qual o ensino de línguas age de forma decisiva. Fortemente relacionado às esferas da cidadania, da discursividade e da formação profissional, o ensino de língua estrangeira, recentemente redefinido no aparato jurídico nacional, parece caminhar nesse sentido.

Nessa era de relações globalizadas e midiatizadas, as razões que levam à adoção de uma política linguística de ensino de línguas estrangeiras são frequentemente de ordem econômica e prática. Não surpreende, portanto, que em diferentes partes do mundo, "os indivíduos possam consumir os mesmos produtos e aderir a valores culturais semelhantes" (GUGLIANO, 2000, p. 65). Nesse sentido, a tendência observada nos sistemas educativos mundiais parece ser o de conceder, cada vez mais, importância às línguas de circulação supranacional como é o caso do inglês.

A mudança efetuada na LDB 9394/96, através da Lei 13.415 de 2017, alterando a política de ensino de línguas no Brasil, segue regiamente essa tendência ao delimitar o inglês como única língua obrigatória em todo o território nacional, a despeito dos diferentes cenários linguísticos existentes no país, entre os quais estão as regiões de fronteira e as regiões histórica e culturalmente constituídas por migrantes e seus descendentes. A política adotada reforça formações baseadas em conhecimentos uniformes, em que a similaridade mundial é a base fundamental na definição dos saberes a serem aprendidos, sem que se leve em conta, por exemplo o princípio da individualidade.

Cabe ressaltar nesse âmbito, que a implementação de uma política linguística educativa (doravante PLE) voltada para uma perspectiva plurilíngue e de equilíbrio social 
deve repousar, antes de tudo, na análise das condições sociais da comunidade, na determinação das necessidades (demanda social, política, mercado linguístico) e nas representações que os falantes guardam das línguas presentes na comunidade e que serão objeto da política linguística prevista.

Especialmente nas regiões de fronteira, o papel das línguas é particularmente marcado por elementos sócio históricos, políticos, culturais e étnicos que forçosamente não são os mesmos de outras regiões dentro de um mesmo Estado-Nação. Elas não apenas contribuem para promover as relações entre países vizinhos diante das problemáticas cotidianas das regiões fronteiriças, mas colaboram decisivamente nas trocas comerciais, nas estruturas de produção, nas formações e curriculum, nas ofertas e escolhas profissionais, entre outros.

O ensino e a aprendizagem de línguas nesses espaços têm particular vinculação com o mercado de trabalho fronteiriço e, portanto, as escolhas lingüísticas não são fruto do acaso, mas expectativas de dar respostas às necessidades específicas, ao mesmo tempo que visam tirar proveito da proximidade com o país vizinho. Entram em jogo igualmente as representações linguísticas que circulam nesses espaços, podendo tanto corroborar políticas linguísticas instituídas quanto fundamentar o surgimento de novas orientações para a gestão das línguas nas sociedades envolvidas.

\section{Representação social e linguística}

As representações sociais -entre as quais as das línguas - se inscrevem em todos os domínios da vida em sociedade e os cidadãos agem em função destas representações. Jodelet (1989, p.361) considera a representação social como "uma forma de conhecimento, socialmente elaborada e partilhada, baseada em uma visão prática que concorre para a construção de uma realidade comum a um grupo social ${ }^{5 \prime \prime}$. Essa ideia de construção coletiva, sendo um dos elementos constitutivos do conceito, reforça a noção de representação como resultado de uma elaboração coletiva no interior de um grupo social.

\footnotetext{
${ }^{5}$ Do original: "une forme de connaissance, socialement élaborée et partagée, ayant une visée pratique et concourant à la construction d'une réalité commune à un ensemble social".
} 
Tal qual as línguas, as representações sociais são ao mesmo tempo construídas e adquiridas e tornam-se elementos de unidade e de identidade de cada comunidade podendo tanto favorecer a adoção de uma política em torno de um objeto social, quanto rejeitá-la. É preciso também observar que em geral essas representações não repousam em fundamentos objetivos, mas em qualidades e virtudes que lhes são atribuídas pelos indivíduos.

Por sua vez, Moliner (2001) afirma que as representações sociais nos permitem compreender e avaliar nosso meio ambiente. Elas teriam um papel capital na construção de nossa visão de mundo. Expressas através desta dimensão essencial da linguagem que é a interação, as representações mediatizam nossa visão de mundo e a realidade que o mundo nos apresenta, posto que nem sempre elas são coincidentes.

Quanto às representações linguísticas, em geral compreende-se que elas correspondem às imagens, opiniões e preconceitos compartilhados por grupos de falantes em uma dada comunidade linguística a respeito das línguas. Tais representações alicerçadas nas interações e nas relações socioculturais alteram-se conforme o contexto em que eclodem e as experiências vivenciadas e/ou projetadas pelos indivíduos e suas comunidades. Cabe salientar igualmente que as representações das línguas não se constituem unicamente da imagem da língua, mas também da percepção que se tem dos nativos que a utilizam, dos usos sociais desta língua na comunidade, das competências de aprendizagem e do aprendente em si mesmo.

Nesse sentido Beacco e Byran (2003, p. 43) afirmam que

\begin{abstract}
De acordo com os grupos sociais, pode haver variações destas representações linguísticas, por exemplo, diferenças de percepção da suposta utilidade de certas línguas entre grupos com forte capital escolar, grupos que residem em regiões fronteiriças, (que estão) em constante contato com falantes de outras línguas, ou grupos que só tem contato esporádico ou indireto com outras línguas além daquelas que eles utilizam ${ }^{6}$.
\end{abstract}

\footnotetext{
${ }^{5}$ Do original: "selon les groupes sociaux, il peut y avoir des variations de ces représentations linguistiques, par exemple, des différences de perception de l'utilité supposée de certaines langues entre des groupes à fort capital scolaire, des groupes résidant dans des régions frontalières, en contact régulier avec des locuteurs d'autres langues, ou des groupes qui ne sont qu'en contact sporadique ou indirect avec d'autres langues que celles qu'ils utilisent $»$.
} 
Para Castelloti e Moore (2002, p. 7), a noção de representação está profundamente relacionada à apropriação e transmissão das línguas. Trata-se da representação que os locutores fazem acerca das línguas, de suas normas, de suas características ou de seus status face a outras línguas, influenciando as estratégias entre o uso e o aprendizado.

Grosso modo, constata-se que as representações sobre as línguas envolvem:

- Grau de dificuldade (facilidade, dificuldade, estranheza);

- Beleza (sonoridade, prestígio, literatura, etc.);

- Utilidade (profissional, pessoal, cultural, etc.);

- Valor educativo (capacidades intelectuais, racionalidade).

Os dados observáveis acessados, mediados pelos "dizeres" e pelo "modo de dizer" levam às representações. É nesse sentido que Harré (1989) entende as palavras como vetores de representações. Na compreensão do autor, o vocabulário, o repertório lexical concernente a um objeto social como as línguas estrangeiras, por exemplo, é um indicador concreto de representações. Com efeito, as palavras, no plano empírico (dos falantes comuns ou dos agentes de decisão), correspondem aos elementos de uma representação no plano teórico.

A escolha das línguas estrangeiras no sistema educativo é também tributária das representações que os membros de uma comunidade (entre os quais os agentes de decisão) construíram a propósito das diferentes funções destas línguas, isto posto, toda política linguística deveria considerar as representações sociais das línguas (BEACCO \& BYRAM, 2003) nas comunidades envolvidas, e nenhuma política de formação em língua estrangeira deveria ignorar, por um lado, os usos sociais das línguas e, por outro, as representações de seus status sociais formais e informais.

De acordo com Poirier (1988), o status formal de uma língua estrangeira corresponde ao papel prestigioso atribuído a uma língua no sistema educativo. 0 status informal é o conjunto de representações que uma coletividade relaciona a uma dada língua. Estes dois status estão fortemente representados nas motivações que levam um indivíduo a querer ou não aprender uma língua estrangeira.

Concebida como um conjunto de dados que incitam à ação, a motivação depende de 
aspectos externos e internos. O aprendente pode ter uma motivação totalmente pessoal para se engajar na aprendizagem de uma língua ou estar motivado pela expectativa de uma recompensa, seja ela profissional ou econômica. Considerando estes dois fatores, Gardner et Lambert (1972) identificam dois tipos de motivação: a motivação "instrumental" e a "integrativa".

A motivação instrumental provém do desejo de obter um reconhecimento social ou de ter "alguma vantagem" prática, concreta da aprendizagem de uma língua. A motivação integrativa, por sua vez caracteriza-se pelas atitudes positivas face aos falantes da língua alvo, como o desejo de integração ou a vontade de conhecê-los. Cabe dizer, no entanto, que estas duas motivações não são excludentes, mas, na maioria das vezes, complementares.

Em uma perspectiva interacionista, ressalta-se que a motivação depende igualmente da interação do indivíduo com o seu meio ambiente linguístico, o que situa diferentemente os aprendentes de uma zona fronteiriça daqueles que não estão frequentemente expostos a uma outra língua ou a uma dada língua, seja no que concerne suas experiências pessoais para com uma língua específica, seja no tocante às representações construídas socialmente em torno de uma língua $X$.

Esta noção de motivação é bastante reveladora neste trabalho, pois atrelada aos projetos individuais, aos objetivos pessoais, à vida cotidiana, às expectativas dos aprendentes e às condições que circundam a aprendizagem da língua, ela compõe, em conjunto com a demanda social em torno da LF no Amapá, um quadro das motivações e representações linguísticas desta língua na fronteira, bem como da política linguística educativa idealizada para a região.

\section{Da metodologia da pesquisa}

Nesta seção, apresentam-se os participantes da pesquisa, os instrumentos de coleta de dados utilizados e o método de análise adotado.

A metodologia adotada no planejamento e realização da pesquisa, bem como a análise dos dados se apoiam nos princípios, regras e técnicas preconizados nas pesquisas de 
natureza exploratória e descritiva, acessando dados simultaneamente quantitativos e qualitativos. Adota-se a perspectiva de Bauer e Gaskell (2000) que defendem que neste tipo de pesquisa não se pode pensar em quantificar sem qualificar. As análises estatísticas demandam uma interpretação, posto que os dados não se revelam por si mesmos.

\subsection{0 contexto da pesquisa}

A pesquisa foi realizada com alunos do Centro Estadual de Língua e Cultura Francesa Danielle Mitterrand - CELCFDM, em Macapá, no Amapá. Criado em 1998, o CELCFDM surge no âmbito das relações transfronteiriças referendadas pelo acordo assinado entre Brasil e França em 1996, em cujos objetivos destaca-se o compromisso de reforço ao ensino da língua portuguesa na Guiana Francesa e do francês no Brasil, particularmente no Amapá.

Desde então, a cada início de ano, o CELCFDM acolhe cerca de 300 novos alunos, através de processo seletivo, dos quais 231 participaram da pesquisa no início do ano letivo de 2015 , quando a Lei 11.161/2005 provocava transformações importantes no sistema de ensino no Amapá. O critério de escolha dos participantes da pesquisa foi a condição de aluno iniciante, oficialmente matriculado no 1 o nível de língua, na tentativa de apreender suas representações sobre a língua, ainda sem a possível influência do discurso dos professores de francês e dos suportes de aprendizagem.

Como instrumento de pesquisa, foi utilizado um questionário dividido em duas partes. Na primeira parte do questionário, foram solicitadas informações do tipo gênero, idade, situação profissional e grau de escolaridade. O objetivo foi traçar um perfil sociológico do público que busca a aprendizagem da LF no Amapá. A segunda parte foi composta de três questões de múltipla escolha concernentes às motivações e expectativas de aprendizagem, sobre a política de ensino de línguas estrangeiras para a zona fronteiriça e uma questão aberta (onde se justifica a escolha da língua estrangeira a aprender). A partir das respostas obtidas para essa última questão é que se propõe efetivamente uma análise das representações denotadas pelo repertório lexical utilizado.

Embora os dados tenham sido coletados em 2015, no auge das repercussões da Lei 11.161 no Amapá, a atualidade das discussões empreendidas a partir da Lei 13415/2017 
recolocam o papel das línguas em contextos de fronteira novamente no cerne das discussões político linguísticas no país.

\section{Apresentação, análise e discussão dos dados.}

\subsection{As variáveis socioprofissionais}

A partir dos questionários respondidos por 231 informantes da pesquisa, podemos constatar uma maioria expressiva de mulheres frequentando o curso de Francês Língua Estrangeira no Centro Danielle Mitterrand. São 70\% de mulheres contra 30\% de homens.

No que diz respeito à idade dos aprendentes, constatou-se que o CELCFDM acolhe pessoas de idades variadas, desde os mais jovens, a partir de 15 anos, idade mínima admitida, até aos de mais idade que desejam aprender o $\mathrm{FLE}^{7}$. Dado que indica que a demanda pela aprendizagem da LF no Estado do Amapá atinge uma ampla faixa etária. O grupo majoritário é aquele dos estudantes entre 18 e 27 anos, eles equivalem a $36 \%$ da clientela. Eles correspondem a uma parcela da sociedade que se encontra em plena vivência do processo de formação profissional, ou seja, são alunos dos anos finais do ensino médio e / ou ingressantes e concluintes do ensino superior. O segundo maior grupo em termos percentuais está na faixa de 28 a 35 anos. Normalmente é um grupo que busca afirmar-se profissionalmente e visa a aperfeiçoar-se na profissão, agregando saberes como o conhecimento de uma LE que possa acrescentar valor às competências adicionais. Em seguida identificou-se dois grupos que apresentam uma equivalência numérica, aqueles dos mais jovens, entre 15 et 17 anos (14\%) e os adultos entre 36 e 50 anos (13\%), grupos bastante distintos entre si, principalmente quanto as suas motivações para aprender uma LE, conforme se pode constatar ao longo deste trabalho.

O grupo minoritário é aquele constituído pelos aprendentes com mais de 50 anos. Eles representam (6\%) de estudantes do CELCFDM.

\footnotetext{
${ }^{7} \mathrm{O}$ aprendente mais idoso participante da pesquisa tinha 68 anos.
} 


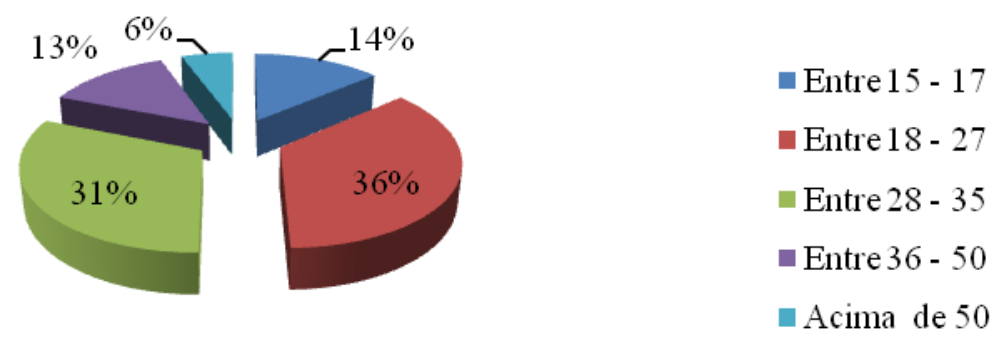

Figura 1: Faixa etária dos estudantes do CELCFDM

Fonte: o autor

Relativamente ao grau de escolaridade, tal qual para a faixa etária, constata-se no CELCFDM uma grande diversidade na comunidade de aprendentes. Inicialmente, dois grupos se destacam, aqueles que já possuem uma formação superior, que correspondem a $29 \%$, e aqueles que apenas completaram seus estudos secundários, que atingem $20 \%$ do conjunto de estudantes. Identificou-se ainda uma participação significativa de estudantes universitários, 17\%, bem como de profissionais com pós-graduação lato ou stricto-sensu que buscam a aprendizagem do FLE com propósitos acadêmicos específicos. Estes equivalem a $15 \%$ dos estudantes do CELCFDM.

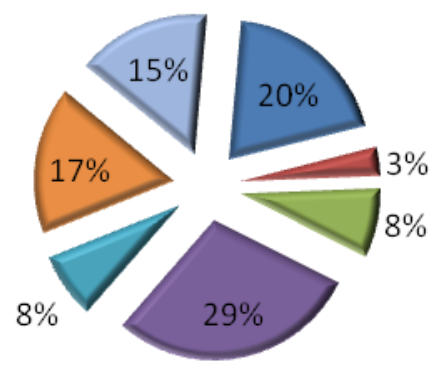
回E. M. completo
回. M. incompleto
口.M. em curso
E. Superior completo
回E. Sup. incompleto
E. Sup. em curso
四 Pós-graduação

Figura 2: Grau de escolaridade dos estudantes

Fonte: o autor

Contam-se ainda, respectivamente, $8 \%$ e $3 \%$ de aprendentes secundaristas e universitários que não terminaram seus estudos. Constata-se, igualmente, que em termos globais, 36\% dos participantes são estudantes em formação, ou seja, que ainda não têm uma profissão definida, mas trabalham e estudam ou que não trabalham e $64 \%$ correspondem a 
profissionais com uma formação técnica de nível médio (20\%) ou de formação superior (29\%), ao que se soma aqueles com pós-graduação (15\%).

Fica evidenciado pelo gráfico que a aprendizagem do francês interessa tanto àqueles que estão em busca de uma atividade profissional quanto àqueles que já contam com uma estabilidade no mercado de trabalho. Estes números testemunham a demanda social em torno da língua francesa, percepção que se reforça igualmente pelo repertório de atividades profissionais desempenhadas pelos estudantes do CELCFDM.

Observou-se, a partir dos dados, que o CELCFDM abriga uma rica diversidade de profissionais dentre a clientela que frequenta o curso de francês. Nesta pesquisa, que atingiu apenas os estudantes do 10 nível, foram constatados 11campos profissionais e 40 profissões diferentes.

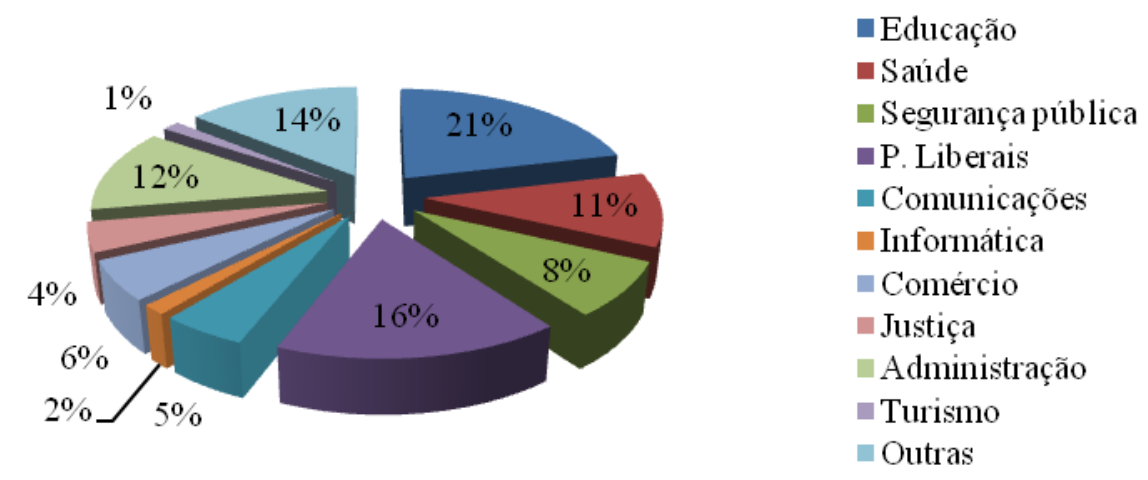

Figura 3: Áreas profissionais dos estudantes do CELCFDM

Fonte: o autor

De juízes a garçons, de militares aposentados ou na ativa a adolescentes em busca de formação profissional, de estudantes de Letras-Francês a motoristas de taxi, todos podem ser encontrados em uma classe de FLE no Centro Danielle Mitterrand, dado que chama a atenção não apenas para a importância acordada à aprendizagem da língua francesa, entre diferentes grupos sociais e classes econômicas diversas, mas também para os diversos domínios profissionais circunscritos na pesquisa, atestando que não se trata de uma demanda setorizada ou restrita a alguns campos de atuação mais relacionados com as 
interações fronteiriças mais imediatas como se poderia supor.

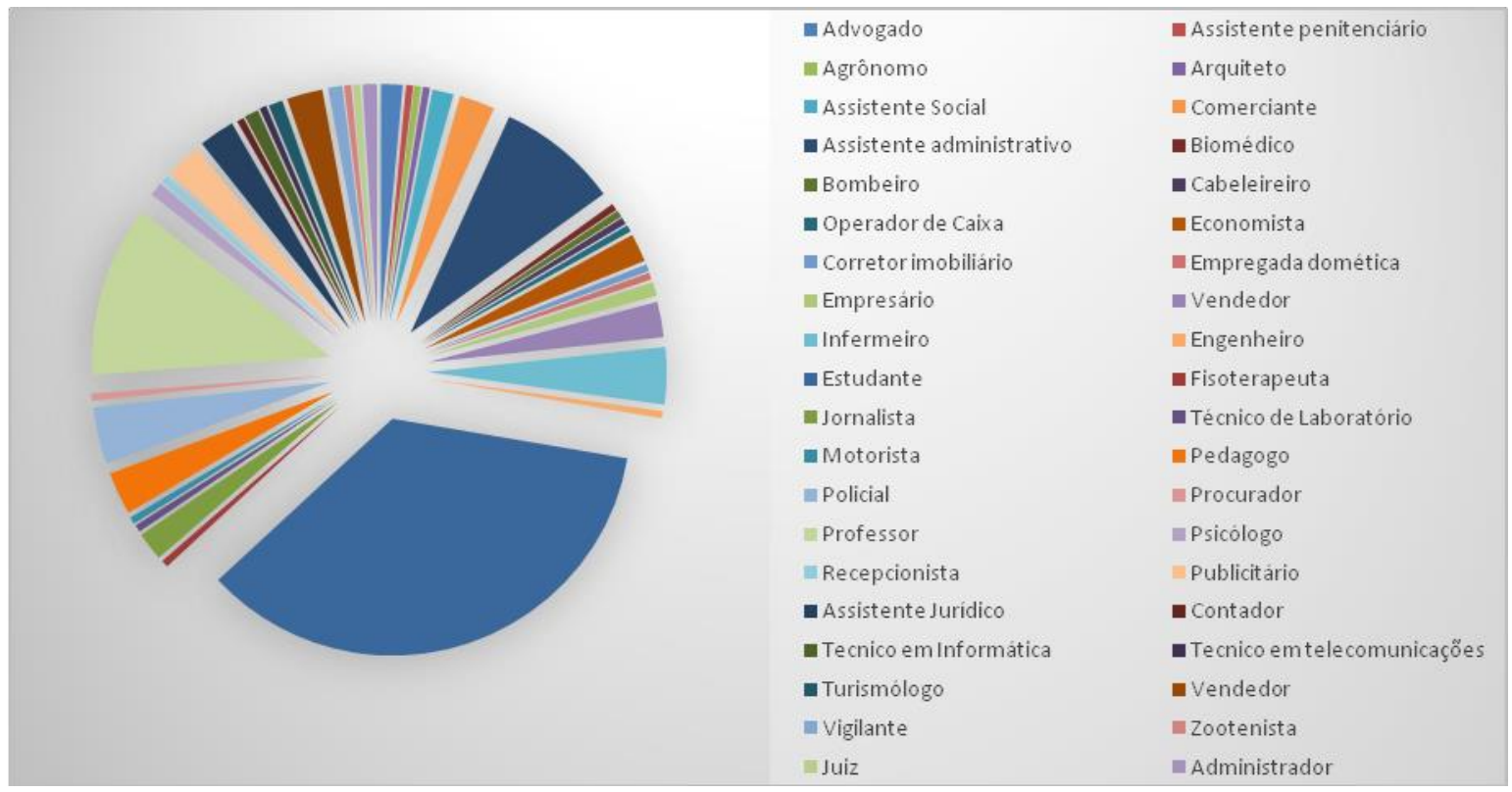

Figura 4: Profissões exercidas pelos informantes

Fonte: o autor

Tais dados nos trazem uma primeira percepção da LF no Amapá: a demanda em torno da aprendizagem dessa língua é observável em diversos grupos sociais, qualquer que seja a idade, o status social, o grau de escolaridade e mesmo o campo profissional. Cabe dizer, nesse sentido, que uma atitude em direção a um objeto social, como uma língua estrangeira, por exemplo, não se faz sem que se tenha como pano de fundo uma representação, seja ela negativa ou positiva desse objeto. Destaca-se o alto índice de estudantes em formação profissional que estudam francês na região, dado que nos permite correlacionar a aprendizagem da língua ao papel que ela desempenha, real ou imaginário, no mercado de trabalho.

5.2 Representação e motivação para a aprendizagem da Língua Francesa no Amapá.

A pesquisa lança luz sobre as representações da "utilidade" do francês no mercado fronteiriço. A opção de abordar apenas a noção de utilidade da língua remete ao objetivo proposto de delimitar as situações de uso vislumbrada pelos aprendentes com relação à 
língua francesa (no trabalho, na família, com amigos, em situações de lazer, nas viagens, entre outros). Obviamente, a língua francesa não se faz presente em todos os domínios da vida social da comunidade amapaense, e, portanto, não apresenta funções utilitárias em todos os âmbitos da vida social, mas permeia o imaginário social em suas representações. Assim, a proposta aqui apresentada se propôs a averiguar, a partir dos dados coletados, em quais domínios os estudantes de francês concebem que essa língua é ou pode ser utilizada.

Estas representações da utilidade de uma língua estão estreitamente ligadas às motivações, posto que o sujeito é sempre motivado pelas ideias nas quais acredita. Assim, considerando a classificação apresentada de motivação de Gardner et Lambert (1972) instrumental ou integrativa-, para a aprendizagem da LF foram sugeridas 5 possibilidades: (1) perspectivas futuras de trabalho, (2) interação com os vizinhos da fronteira, (3) o trabalho atual, (4) o desejo de viajar para países de expressão francófona e (5) a vontade de visitar (amigos ou família) ou habitar na Guiana, além da possibilidade dada ao informante de apontar uma outra motivação diferente daquelas indicadas no questionário.

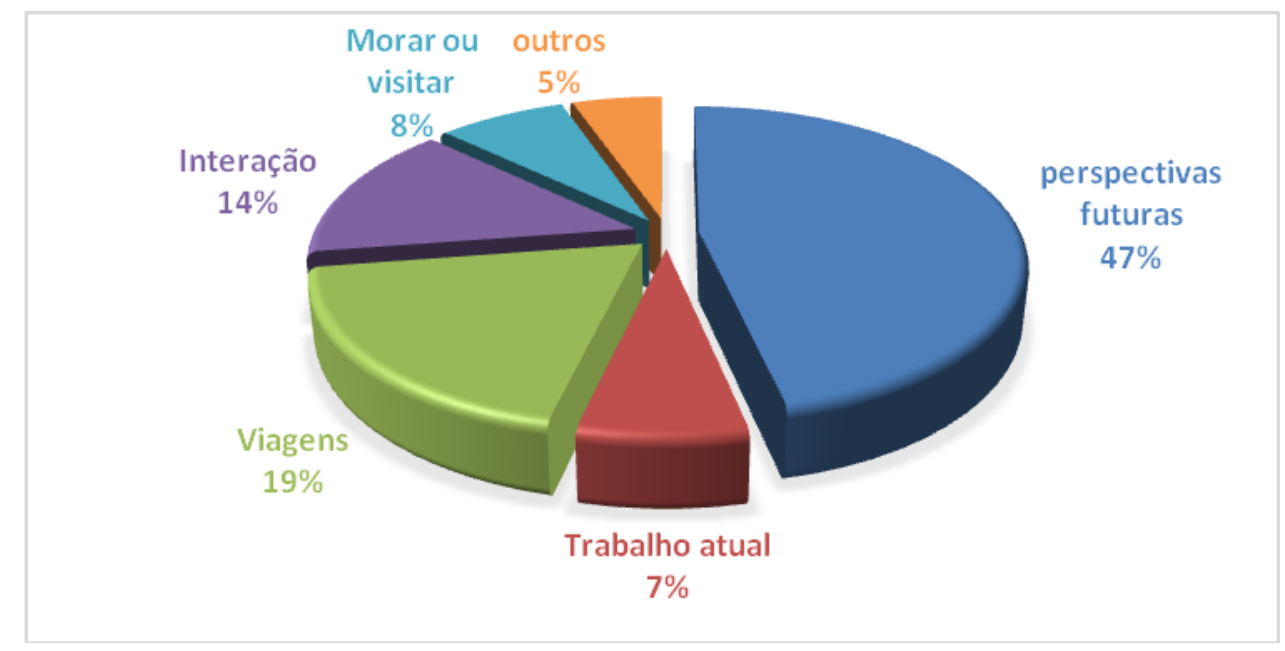

Figura 5: motivações para a aprendizagem da LF no Amapá Fonte: o autor

A maioria dos estudantes, $47 \%$, relaciona a aprendizagem da LF a perspectivas futuras de trabalho, ou seja, desenvolver competências linguísticas em LF é entendido como uma característica importante no mercado de trabalho tanto para aqueles que já desenvolvem 
uma atividade profissional, quanto para aqueles em formação. Estudantes e profissionais liberais (médicos, advogados, arquitetos, etc.) são aqueles que demonstram ter mais incorporada essa representação da LF, sendo continuamente motivados por ela. Esta mesma percepção é partilhada também por profissionais atuantes no mercado e que demonstram necessidades mais imediatas de aprendizagem da língua, em especial os trabalhadores do comércio e do turismo, $7 \%$.

Aprendentes com carreiras estáveis e públicas compreendem a LF como elemento importante para a interação social, ou seja, como instrumento de integração regional. Para este grupo, de 13\%, interagir com os vizinhos franco-guianenses é a principal função social da LF no Amapá, sendo esta a motivação mais comumente referenciada por policias, bombeiros, técnicos administrativos, agentes de saúde, entre outros.

Em outra perspectiva, $19 \%$ dos estudantes do CELCFDM, entre eles se destacam os profissionais aposentados, estudantes universitários, jornalistas, juízes e médicos, estimam que a LF é também "passaporte" para conhecimento de países francófonos.

Visitar amigos e familiares ou morar futuramente na França ou na Guiana Francesa aparece como motivação principal para $8 \%$ dos estudantes. Outras motivações como "leitura", para provas de proficiência em seleções de mestrado e de doutorado, para acesso a textos de áreas de conhecimentos específicos como o das artes, meio ambiente, literatura, etc. representam $5 \%$ das motivações apresentadas.

Assim, observa-se a existência tanto de motivações instrumentais quanto integrativas, qualquer que seja o objetivo da aprendizagem da língua vislumbrado. Em outras palavras, dentre a maioria que planeja utilizar a LF em contexto profissional, há tanto aqueles que visam atingir benefícios econômicos (melhores salários, vagas no mercado de trabalho, conquistar novos clientes) quanto aqueles que estimam melhor interagir, seja no ambiente de trabalho, seja nas relações interpessoais com falantes nativos da comunidade fronteiriça.

Diante dos dados apresentados, constata-se ainda duas representações relativas à utilidade da LF no Amapá, uma que se vincula aos usos possíveis nos domínios profissionais no mercado de trabalho e uma segunda ligada às funções integrativas e interativas entre os povos da fronteira, que também se aliam às vontades individuais. 


\subsection{Competências linguísticas a desenvolver}

Das representações das línguas emanadas do domínio profissional surgem expectativas de desenvolvimento de competências linguísticas. Os dados analisados permitem afirmar que $94 \%$ dos estudantes alimentam a expectativa de desenvolver as 4 (quatro) competências linguísticas, ou seja, desejam aprender a ler, escrever, falar e compreender em LF. Os índices daqueles que apontam necessidade específicas de leitura ou apenas de comunicação oral restringem-se respectivamente a $5 \%$ e $1 \%$ dos participantes. Estes dados indicam que as competências visadas se vinculam igualmente à utilização da língua em diversos domínios de aplicação, diferentes situações de comunicação, bem como em vista de diferentes objetivos a atingir.

5.4 Da escolha das línguas e da política linguística educativa nacional

Questionados quanto a quais línguas deveriam figurar como obrigatórias no sistema de ensino, observou-se que na mesma linha das representações e motivações observadas, as preferências linguísticas da comunidade amapaense reforçam a função utilitária aplicada à LF e o papel onipresente do inglês como língua internacional.

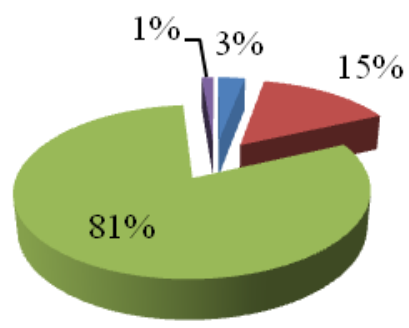

$$
\begin{aligned}
& \text { - Inglês e Espanhol } \\
& \text { Francês e Espanhol } \\
& \text { Inglês e Francês } \\
& \text { As três linguas }
\end{aligned}
$$

Figura 6: Línguas preferenciais Fonte: o autor

Inglês e francês aparecem nos dados como as línguas prioritárias para $81 \%$ dos 
informantes. 15\% prefeririam ter como LE obrigatória no sistema escolar de ensino, o francês e o espanhol, 3\% registraram preferência pelo inglês e espanhol e 1\% indicam a preferência pela obrigatoriedade das três LE ofertadas na rede de ensino. Observa-se, portanto, que para 96\% dos estudantes entrevistados, a LF deveria ter caráter de obrigatoriedade institucionalizado na rede de ensino local, ideia frontalmente em oposição ao que foi delimitado na legislação nacional para o ensino de línguas em seus dois últimos instrumentos legais de regulação.

5.4.1 Da Representação das línguas a partir do léxico.

Outro destaque observável nos dados concerne a compartimentalização delimitada de usos e papeis das línguas (Espanhol, Francês e Inglês) na região. Os dados são oriundos dos termos utilizados para justificar a escolha das línguas preferenciais na região, conforme demonstrado na figura 7:

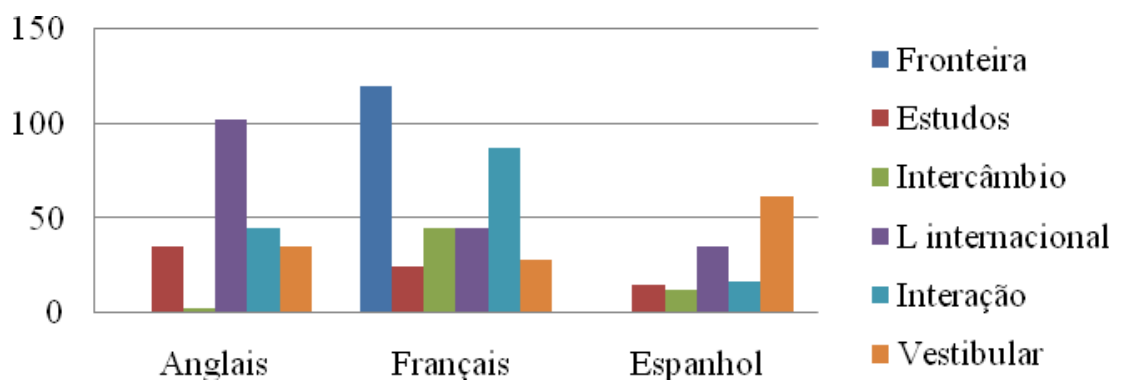

Figura 7: Termos referentes às línguas

Fonte: o autor

O termo "fronteira" foi o mais mencionado correlativamente à língua francesa; "internacional" é o vínculo predominante relacionado ao inglês; e "ENEM" a palavra mais frequentemente encontrada para justificar o ensino do espanhol. Estas noções remetem àquelas do status formal e informal das línguas.

O status formal de obrigatoriedade acordado ao espanhol pela Lei 11.161/2005, não Ihe concedia, aparentemente, nenhum lugar de utilidade objetiva na fronteira franco- 
brasileira, senão aquela relativa à avaliação de LE no ENEM.Em contrapartida, as noções de fronteira e mesmo a de internacionalização, conduzem a representações mais atreladas a necessidades reais de comunicação (trabalho, interação, viagens).

Evidentemente estes dados não desqualificam ou desconsideram o papel que a língua espanhola exerce globalmente nos dias atuais e, principalmente, na América Latina, mas tão somente apresentam um deslocamento da visão situada de uma comunidade fronteiriça, onde o espanhol não remete às mesmas funções sociais desempenhadas em outras fronteiras brasileiras. Na fronteira franco-brasileira, o francês surge nos dados, expressivamente relacionado aos intercâmbios comerciais, às interações cotidianas e aos estudos, atividades presentes e com altas probabilidades de realização.

Uma aparente contradição observada nos dados é relativa à representação da língua inglesa. Embora haja uma vinculação ao seu caráter de internacionalidade, essa mesma língua não é majoritariamente vista como facilitadora das trocas linguísticas na região, fator que deixa entrever que apesar de seu prestígio inconteste, ela surge ainda mais distanciada que o espanhol dos usos cotidianos da fronteira. Sua onipresença aparece muito mais como uma construção coletiva subjetiva, presente no inconsciente coletivo do que como fruto de experiências sólidas de uso dessa língua na fronteira.

\section{Considerações finais.}

Este estudo teve como objetivo traçar o perfil sociológico dos estudantes de francês do Centro de Língua e Cultura Francesa Danielle Mitterrand,no Amapá, analisar as motivações que geram as demandas pelo ensino da língua francesa na região, identificar as representações relativas às línguas ofertadas nas redes de ensino para correlacionar motivações e representações linguísticas com o papel da LF na formação profissional dos habitantes da fronteira franco-brasileira, afim de contextualizar o ensino de línguas nessa fronteira no âmbito da política linguística educativa nacional.

Como fenômenos cognitivos, as representações sociais interferem no grupo social, nos sentimentos e deveres de cada membro do grupo e na construção do conhecimento e do comportamento do indivíduo. É nesse sentido que se constata que a demanda de um grupo 
social -no Amapá, por exemplo- de uma dada língua -o francês- é tributário da representação coletivamente construída em torno desta língua na região.

A decisão tomada voluntariamente pelos locutores (de aprender ou não, essa língua) assim como as percepções dos papeis sociais da língua francesa na região (sua utilidade, sua importância, seus usos) testemunham a importância da adoção de políticas linguísticas educativas que privilegiem os contextos sociais, o que não é o caso, atualmente, na região em questão.

As representações do francês, do inglês e do espanhol, coletivamente elaboradas pelos aprendentes do francês no CELCFDM, foram construídas em torno das relações transfronteiriças Amapá-Guiana Francesa e das imagens que circulam na comunidade internacional correlativamente ao inglês e ao espanhol. Estas representações nos parecem determinantes na gestão das relações sociais, tanto no que concerne às condutas quanto às práticas comunicativas.

Dado que as representações sociais guiam, de alguma forma, os comportamentos de um grupo com relação às línguas, seria muito importante considerar as atitudes favoráveis relativas ao francês no Amapá para a construção de uma política linguística educativa tanto mais adequada ao meio ambiente transfronteiriço e às necessidades sociocomunicativas dos indivíduos.

A promoção do conhecimento de línguas estrangeiras nas regiões fronteiriças deve utilizar a oportunidade que oferece a vida cotidiana para fazer das línguas um meio de intercâmbio de interesses, de pontos de vista e de comportamentos específicos e, frequentemente, diferentes.

A partir das reflexões propostas neste artigo, que tomam como cenário a fronteira franco-brasileira e contextualizam aspectos da política linguística educativa nacional, esperamos não apenas estimular outras pesquisas em contextos diversos, mas também colocar em discussão os direcionamentos que se apontam para o ensino de línguas no Brasil obliterando as diferentes realidades socioculturais e mesmo socioeconômicas brasileiras.

\section{Referências}


BAUER, M. W; GASKELL, G. Qualitative researching wich text, image and sound. A pratical handbook. London: Sage, 2000.

BEACCO, J-C; BYRAM, M. Guide pour l'élaboration des politiques linguistiques em Europe: de la diversité linguistique à l'éducation plurilingue. Division de politiques linguistiques. Conseil de l'Europe, Strasbourg, 2003.

CALVET, L-J. As políticas linguísticas. Tradução Isabel Duarte, Jonas Tenfen, Marcos Bagno São Paulo: Parábola Editorial: Ipol, 2007.

CASTELLOTTI, V; MOORE, D. Représentations sociales des langues et enseignement. Étude de référence. Division des politiques linguistiques, Conseil de l'Europe, Strasbourg, 2002.

GARDNER, R. C; LAMBERT, W. E. Attitudes and Motivation in Second Language Learning, Rowley, Massachusetts, Newbury House Publishers, 1972.

GUGLIANO A. Nas costas da globalização: as perspectivas dos países periféricos frente as transformações da economia internacional. In M. Ferreira; A. Gugliano (org.). Fragmentos da globalização na educação. Porto Alegre: ArtMed., 2000, pp. 63-76.

HARRÉ, R. Grammaire et lexiques, vecteurs des représentations sociales. Dans JODELET (ed). Les Représentations sociales. Paris: Presses Universitaires de France, 2011, pp. 131-151.

JODELET, D. Representações Sociais. Rio de Janeiro: EDUERJ, 2001.

MOLINER, P. Images et représentations. De la théorie des représentations à l'étude des images sociales. Grenoble: PUG, 1996

MOLINER, P. La dynamique des représentatios sociales. Grenoble: Presses Universitaires de Grenoble, 2001.

PACHECO, J. A; PEREIRA, N. Globalização e identidade educativas. Rupturas e Incertezas. In: Revista Lusófona de Educação, 8, 2006, pp.13-28.

PETITJEAN, C. Représentation linguistiques et Plurilinguisme. These de doctorat. $488 \mathrm{fls}$. Faculté de lettres et sciences humaines, Université de Nauchâtel, 2009.

POIRIER, F. "Les stéréotypes", In: CAIN, Albane (ed.), L'enseignement de la civilisation (langues vivantes, second cycle), Paris: INRP, 1988, pp. 29-45.

SPINK, M. J. P. The Concept of Social Representations in Social Psychology. Cad. Saúde Públ., Rio de Janeiro, 9 (3): 300-308, jul/sep, 1993.

WAGNER, W. Social representations and beyond: Brute facts, symbolic coping and domesticated words. In: Culture and psychology, 1998. 4 (3), pp. 297-329. 
ZARATE, G. Représentations de l'étranger et didactiqu edes langues. CREDIF, Collection Essais, Paris: Didier, 1993.

Data de submissão: 21/04/2019. Data de aprovação: 16/05/2019. 